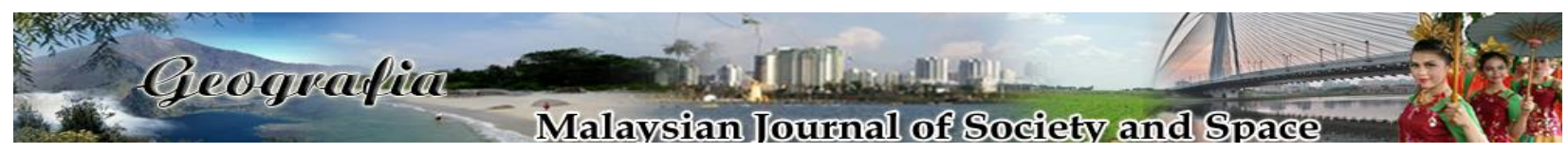

\title{
Pengetahuan agropreneur terhadap potensi sisa substrat cendawan dan kaedah pengurusan lepas tuai tanaman cendawan
}

\author{
Rosmiza M.Z., Juliana Mah Hussin, Mimi Halida Ghazali \\ Program Geografi, Pusat Pembangunan, Sosial dan Persekitaran, Fakulti Sains Sosial dan Kemanusiaan, \\ Universiti Kebangsaan Malaysia \\ Correspondence: Rosmiza Mohd Zainol (e-mail: miza@ukm.edu.my)
}

Received: 31 May 2019; Accepted: 17 August 2019; Published: 22 August 2019

\begin{abstract}
Abstrak
Konsep pembangunan pertanian mampan memberi keutamaan terhadap pertimbangan alam sekitar, pembangunan ekonomi dan keperluan sosial dalam proses pengeluaran hasil tani. Proses ini melibatkan pengurusan tanaman sehinggalah lepas tuai yang perlu diurus secara mesra alam. Merujuk kepada tanaman cendawan, ianya merupakan sejenis tanaman yang mesra alam kerana substrat pertumbuhannya terdiri daripada sisa pertanian lain, manakala sisa lepas tuai iaitu sisa substrat cendawan (SMS) boleh digunakan semula untuk pembangunan aktiviti huluan dan hiliran. Pengurusan tanaman secara tidak mesra alam memberi impak negatif terhadap persekitaran tani seperti pencemaran udara dan bau. Oleh itu, kajian dilakukan untuk menilai tahap pengetahuan agropreneur terhadap potensi penggunaan semula SMS dan kaedah pengurusan lepas tuai tanaman yang diamalkan. Gabungan kaedah kuantitatif (survei) dan kualitatif (temu bual) dijalankan ke atas agropreneur yang mengusahakan tanaman cendawan secara komersil di Kedah (36 agropreneur) dan Johor (42 agropreneur). Hasil kajian mendapati majoriti agropreneur mengetahui SMS boleh digunakan semula sebagai baja kompos, substrat semaian tanaman dan vermikompos. Namun begitu, kaedah pengurusan lepas tuai yang dipraktikkan oleh agropreneur adalah secara tidak mesra alam iaitu melonggokkan SMS dan sisa beg cendawan di tempat pembuangan yang terbuka dan tidak teratur ataupun dibakar secara terbuka. Hal ini menyebabkan berlakunya pencemaran ke atas persekitaran tani. Oleh itu, pendedahan terhadap konsep penjanaan kekayaan daripada sisa buangan dan perniagaan tani secara hijau perlu diterapkan kepada agropreneur melalui pembangunan aktiviti hiliran. Aktiviti ini berupaya meningkatkan pendapatan agropreneur melalui pengurangan kos pembelian input, penjanaan pendapatan sampingan serta pemeliharaan persekitaran tani melalui pengurusan tanaman cendawan secara mesra alam.
\end{abstract}

Kata kunci: agropreneur, cendawan, mesra alam, pengurusan lepas tuai, persekitaran tani, sisa substrat cendawan 


\title{
Agriprenuer's knowledge on the potential of spent mushroom substrate and post-harvest management methods of mushroom cultivation
}

\begin{abstract}
The concept of sustainable agriculture development gives priority to environmental considerations, economic development and social needs in the process of crop production. This process involves crop management up until the post-harvest, which needs to be managed in an environmentally friendly way. In regards to mushroom cultivation, it is an environmentally friendly crop as its growth substrate comprises other agricultural wastes, while the post-harvest waste, which is the spent mushroom substrate (SMS) can be reused for the development of upstream and downstream activities. Environmentally unfriendly crop management has a negative impact on agricultural environment such as air and odour pollution. Therefore, a study has been conducted to assess the level of knowledge of agripreneurs on the potential of reusing SMS and the post-harvest management methods practiced by agripreneur. A combination of the quantitative (survey) and qualitative methods (interviews) was carried out on agripreneur who were working on mushroom cultivation commercially in Kedah (36 agripreneurs) and Johor (42 agripreneurs). Results showed that the majority of the agriprenuers knew that SMS could be reused as compost, plant seed substrate and vermicompost. However, the post-harvest management methods practiced by the agripreneur were environmentally unfriendly, which was done by piling up SMS and mushroom waste bags in an open and unorganized dumping area or burning it openly. This resulted in pollution of the agricultural environment. Therefore, exposure to the concept of waste-to-wealth and green agribusiness should be instilled upon agripreneur through the development of downstream activities. This activity is capable of raising the income of agripreneur by reducing the purchasing cost of inputs, generating side income and preserving the agricultural environment through environmentally friendly mushroom cultivation management.
\end{abstract}

Keywords: agropreneur, mushroom, environmentally friendly, post-harvest management, farming environment, spent mushroom substrate

\section{Pengenalan}

Asia merupakan pengeluar cendawan terbesar dunia yang ditunjangi oleh negara China sebagai pengeluar utama. Genera cendawan Shiitake (Lentinula), Tiram (Pleurotus), Telinga kera (Auricularia), Butang (Agaricus) dan Enoki (Flammulina) mendapat permintaan tinggi dunia dengan anggaran 85 peratus (Royse \& Baars, 2017). Permintaan tinggi terhadap cendawan berikutan perubahan gaya hidup masyarakat yang lebih mementingkan pemakanan sihat (Grimm \& Wösten, 2018), perubatan alternatif serta penggunaan produk kosmetik berasaskan herba (Rosmiza et al., 2018). Hal ini berikutan potensi cendawan dalam industri farmaseutikal, nutraseutikal dan kosmeseutikal semakin berkembang pesat (Mohd Tarmizi et al., 2013; Rosmiza et al., 2018). Lantaran permintaan tinggi di Malaysia menyebabkan cendawan ditonjolkan sebagai salah satu daripada tujuh tanaman industri bernilai tinggi negara dalam Dasar Agromakanan Negara 2011-2020 (Kementerian Pertanian dan Industri Asas Tani, 2011). 
Permintaan yang tinggi terhadap cendawan menjadikan tanaman ini perlu diurus secara efektif dan mesra alam dalam proses pengeluaran hasil tani sehinggalah kepada pengurusan lepas tuai. Hal ini bagi menjamin kemampanan alam sekitar, di samping perkembangan ekonomi serta sosial setempat kesan pembangunan pertanian di sesebuah kawasan. Konsep ini mengutamakan pertimbangan alam sekitar dalam proses pengeluaran hasil, selain memfokus kepada pembangunan ekonomi dan keperluan sosial penduduk. Bagi mencapai tujuan tersebut, konsep penjanaan kekayaan daripada sisa buangan (waste-to-wealth) dan perniagaan tani secara hijau (green agribusiness) perlu diterapkan dalam kepelbagaian dimensi pengurusan sumber dan tanaman oleh agropreneur.

Dalam konteks tanaman cendawan, pengurusan sisa lepas tuai tanaman terdiri daripada dua kategori iaitu sisa substrat cendawan (Spent mushroom substrate/ SMS) dan sisa beg cendawan. Amalan tradisi yang dilaksanakan oleh agropreneur dalam pengurusan lepas tuai tanaman cendawan adalah dengan membakar sisa tanaman, membuang atau melonggokkan sisa tersebut secara tidak teratur di sesebuah kawasan. Kaedah ini menyebabkan berlakunya pencemaran ke atas alam sekitar terutamanya pencemaran udara dan air (Grimm \& Wösten, 2018; Rosmiza et al., 2018). Oleh itu, kajian ini meneliti tahap pengetahuan agropreneur terhadap potensi penggunaan SMS, selain menilai kaedah yang dipraktikkan dalam pengurusan lepas tuai tanaman. Pengurusan lepas tuai tanaman cendawan ini melibatkan pengurusan SMS dan sisa beg cendawan.

\section{Kajian literatur}

Amalan pertanian secara mesra alam melalui penerapan konsep penjanaan kekayaan daripada sisa buangan dan perniagaan tani secara hijau mampu menyumbang kepada pengekalan persekitaran tani yang selamat untuk didiami. Perkara ini berupaya dicapai melalui pengoptimuman penggunaan hasil tani, mengamalkan sistem pengeluaran secara bersepadu, kawalan biologi dalam pengeluaran hasil dan penerokaan potensi sisa pertanian di peringkat aktiviti atau industri huluan dan hiliran (Bharani et al., 2019; Josephine, 2014; Rosmiza et al., 2015; Naresh, 2013; Xu et al., 1992). Menurut Laufenberg et al. (2003), konsep pengeluaran secara holistik perlu diguna pakai dalam pengurusan tanaman dan lepas tuai. Konsep ini bermatlamat untuk meningkatkan kualiti dan keselamatan produk, keefisienan yang tinggi dalam pengeluaran serta mengintegrasikan aspek persekitaran dalam pembangunan produk dan pengeluaran makanan. Merujuk kepada tanaman cendawan, mengintegrasikan pengurusan tanaman cendawan dengan menggunakan semula sisa tanamannya iaitu SMS sebagai makanan ternakan, baja tanaman, agen penyuburan tanah dan pengukuhan struktur tanih, sumber enzim kepada kawalan patogen tumbuhan secara biologikal dan sumber bioremediasi untuk mengatasi masalah pencemaran. Malahan, pembangunan industri huluan dan hiliran sub-sektor tanaman cendawan ini berupaya mengukuhkan ekonomi, sistem ekologi dan nilai tambah serta biotransformasi bagi pembangunan industri berasaskan hasil tani (Philippoussis, 2009).

Industri cendawan merupakan sebuah perusahaan yang mesra alam dalam proses pengeluaran hasil (Beetz \& Kustudia, 2004; Oluwalana et al., 2016; Rosmiza et al., 2018). Substrat (media) utama pertumbuhan tanaman ini menggunakan sisa buangan tanaman lain seperti habuk kayu, jerami dan sekam bagi tanaman bijirin, daun pisang, sisa kapas, sisa tanaman jagung iaitu tongkol dan sekam (Elenwo \& Okere, 2007) serta kulit biji koko (Beetz \& Kustudia, 2004; Hoa et al., 2015; Mamiro \& Mamiro, 2011; Marshall \& Nair, 2009; Oluwalana et al., 2016; Rosmiza et al., 2016; Thongklang \& Luangharn, 2016). Selain itu, hampas tebu, sekam, 
kekacang (Mamiro \& Mamiro, 2011) serta sisa teh (Pani et al., 1997) juga digunakan sebagai substrat bagi pertumbuhannya. Sisa pertanian daripada tanaman kelapa sawit seperti daun, tandan sawit kosong dan fiber turut sesuai dijadikan sebagai substrat tanaman cendawan (Rosmiza et al. 2018; Triyono et al., 2019).

Lantaran itu, sisa lepas tuai tanaman cendawan iaitu SMS mengandungi sumber nutrien yang tinggi kerana media semaiannya diperolehi daripada sisa tanaman lain (Rosmiza et al., 2018) yang mengandungi lignoselulosa (lignocellulose) yang terdiri daripada selulosa (cellulose), hemiselulosa (hemicellulose) dan lignin (Hoa et al., 2015; Mamiro \& Mamiro, 2011; Oluwalana et al., 2016), pektin (pectin), polisakarida (polysaccharides) serta nutrien lain (Dang Lelamurni, 2013). Kedapatan nilai nutrien yang tinggi ini menjadikan SMS berpotensi mempunyai nilai rantaian untuk dimajukan sebagai produk bernilai dalam pembangunan aktiviti huluan dan hiliran selepas proses penuaian (Naresh, 2013; Oluwalana et al., 2016; Tuhy et al., 2015). Penggunaan semula SMS ini berupaya mengurangkan kesan pengurusan sisa ini terhadap alam sekitar dan kesihatan manusia. Tambahan pula, pembangunan aktiviti huluan dan hiliran ini berupaya mengembangkan ekonomi kawasan luar bandar, selain membuka peluang pekerjaan terutamanya kepada golongan wanita dan belia (Josephine, 2014; Kumar et al., 2013; Peng, 2010; Tesfaw et al., 2015; Tuhy et al., 2015).

Sisa substrat cendawan ini berpotensi untuk dimajukan kerana mengandungi kapasiti pertukaran kation yang tinggi; nilai nutrien yang tinggi; dan kadar mineralisasi yang rendah. Kelebihan ini menjadikannya mampu untuk mengekalkan kualiti bahan organik atau sumber nutrien yang terdapat dalam sisa substrat tersebut (Ahlawat \& Sagar, 2011). Kandungan nilai nutrien iaitu nitrogen $(\mathrm{N})$, fosforus $(\mathrm{P})$ dan potassium $(\mathrm{K})$ dalam SMS sangat efektif dimajukan sebagai baja organik atau kompos dan vermikompos (Ahlawat \& Sagar, 2007; Grimm \& Wösten, 2018; Nik Nor Izyan et al., 2009; Ma, et al., 2014). Baja organik ini amat sesuai untuk pembangunan sub sektor pertanian terutamanya tanaman hortikultur serta herba (Ahlawat \& Sagar, 2007; Ahlawat \& Tewari, 2007; Marshall \& Nair, 2009; Marques et al., 2014; Zhang et al., 2014). Penggunaan SMS sebagai baja terbukti mampu meningkatkan tahap kesuburan tanah (Food and Fertilizer Technology Center, 2002; Lou et al., 2017; Taiwan Agricultural Research Institute, 2012; Yildiz et al., 2002; Zheng et al., 2002); pertumbuhan vegetatif dan pengeluaran hasil; pembentukan tangkai yang lebih tinggi; peningkatan ketinggian tanaman; pengukuhan kualiti berat dan keteguhan buah; mengurangkan serangan penyakit tanaman dan serangga serta meningkatkan hasil ladang (Ahlawat \& Sagar, 2007). Malahan, SMS berupaya bertindak sebagai bahan kawalan penyakit tanaman secara biologikal (Meera et al., 2014).

Penggunaan semula SMS sebagai substrat pertumbuhan cendawan lain mampu menjadikan pertumbuhan cendawan lebih subur dan hasil pengeluaran lebih tinggi (Ashrafi et al., 2014; Josephine, 2014; Oei et al., 2007; Siddhant \& Singh, 2009; Yoshida et al., 1993). Kajian oleh Royse (1992) mendapati konsentrasi lignoselulosa yang terdapat dalam SMS selepas tuaian cendawan Shiitake (Lentinus endodes) adalah tinggi iaitu mengandungi hemiselulosa (85.0\%), selulosa (44.0\%) dan lignin (77.0\%). Kandungan lignoselulosa yang tinggi ini amat sesuai digunakan semula sebagai substrat pertumbuhan cendawan lain terutamanya cendawan tiram. Kajian lain oleh Taiwan Agricultural Research Institute (2012) turut membuktikan bahawa hasil pengeluaran cendawan Shiitake meningkat melebihi 20 peratus dengan penggunaan satu pertiga SMS cendawan Tiram raja (Pleurotus eryngii) sebagai substrat pertumbuhan berbanding penggunaan sisa tanaman lain.

Potensi SMS juga berupaya membaiki kandungan fizikal dan kimia tanih; struktur tanih (Ehtesham \& Vakili, 2015; Naresh, 2013); membaiki tekstur tanih; menguatkan kapasiti 
pegangan air; mengukuhkan tahap keliangan tanih; serta meneutralkan tahap keasidan tanih (Ahlawat \& Sagar, 2007). Malahan, mampu mengekalkan keperluan nutrien yang diperlukan oleh tanaman serta menyeimbangkan permintaan ekologi terhadap sistem pengeluaran tanaman (Naresh, 2013). Kajian lain terhadap penggunaan SMS sebagai media tanaman rumput (turf) mendapati SMS berupaya membaik pulih struktur tanih; mengurangkan keretakan dan kepadatan tanih; meningkatkan saliran air dalam tanah; meningkatkan aktiviti mikrob; meningkatkan nutrien rumput; mengukuhkan ketumpatan dan warna rumput; membanyakkan pertumbuhan akar serta mengurangkan penggunaan baja dan pengairan (Landschoot \& McNitt, 2019).

SMS juga mampu bertindak sebagai sumber alternatif kepada bahan api fosil. Kajian oleh Oei et al. (2007), Ma et al. (2014) dan Pérez-Chávez et al. (2019) mendapati SMS telah dibangunkan dengan jayanya sebagai sumber bahan bakar, pengegasan (gasification) (Finney et al., 2009), biogas dan gas metana untuk tujuan pemanasan dan bahan api domestik. Menurut Meera et al. (2014), penghasilan biogas daripada SMS ini berupaya menjimatkan penggunaan tenaga elektrik di kawasan luar bandar.

Namun begitu, potensi sumber ini sering diabaikan dan dibaziri melalui pengurusan lepas tuai secara tidak efisien. Sisa tanaman ini dianggap sebagai bahan buangan pertanian (Grimm \& Wösten, 2018; Laufenberg et al., 2003; Rosmiza et al., 2015, Tuhy et al., 2015). Bagi setiap penuaian satu kilogram cendawan, dianggarkan sebanyak empat hingga lima kilogram SMS akan terhasil (Law et al., 2003; Medina et al., 2012; Phan \& Sabaratnam 2012; Uzun, 2004). Agropreneur sering kali memilih kaedah paling mudah dan murah dalam menangani pengurusan lepas tuai. Kaedah yang sering dipraktikkan dalam pengurusan SMS dan sisa beg cendawan ialah dengan melonggok atau membuangnya di tempat pembuangan lain yang tidak teratur, membakarnya secara terbuka, ataupun ditanam ke dalam tanah (Chang \& Wasser, 2017, Naresh, 2013; Phan \& Sabaratnam, 2012; Rinker, 2005; Rosmiza et al., 2018). Hal ini menimbulkan kerugian dari segi mengoptimumkan penggunaan sisa tanaman berpotensi. Walau bagaimanapun, pengurusan SMS secara mesra alam bergantung kepada keadaan SMS atau bongkah cendawan, sama ada diserang penyakit dan serangga perosak, cuaca serta sikap agropreneur yang mementingkan alam sekitar atau sebaliknya (Rosmiza \& Juliana, 2017).

Pengurusan SMS dan sisa beg cendawan menjadi cabaran utama yang perlu dihadapi oleh agropreneur dalam mempraktikkan pengurusan lepas tuai tanaman cendawan secara mesra alam. Pengurusan lepas tuai ini menjadi lebih mencabar apabila tanaman diserang penyakit dan perosak. Kaedah pembakaran perlu dilakukan apabila bongkah substrat diserang penyakit dan serangga perosak. Kaedah ini dilakukan bagi membunuh sepenuhnya benih penyakit atau serangga perosak daripada menyerang tanaman cendawan berikutnya. Selain pembakaran, SMS dan sisa beg cendawan juga akan dibuang di kawasan yang agak jauh dari rumah cendawan bagi mengelakkan penularan penyakit tanaman (Rosmiza \& Juliana, 2017).

Kaedah yang sering dipraktikkan ini menimbulkan gangguan ke atas alam sekitar seperti pencemaran sumber air bawah tanah dan gangguan udara persekitaran melalui pelepasan bau yang kurang menyenangkan, jika tidak ditangani dengan sempurna (Ahlawat \& Sagar, 2007; Ehtesham \& Vakili, 2015; Grimm \& Wösten, 2018; Philippoussis, 2009; Rosmiza et al., 2016). Tambahan pula, kandungan debu (ash) SMS yang tinggi menjadikan proses pembakaran kurang efektif. Hal ini mewujudkan masalah pengurusan sisa pembuangan dan kesan yang baharu seperti penyebaran habuk terampai di udara (Finney et al., 2009). Selain itu, pengurusan SMS dan sisa beg cendawan yang tidak mesra alam turut menjejaskan kesihatan awam (Josephine \& Sahana, 2014; Rinker, 2002; Rosmiza et al., 2016). 
Kelebihan penggunaan semula SMS yang ditonjolkan ini memerlukan agropreneur mempunyai tahap pengetahuan yang tinggi terhadap potensi yang boleh dibangunkan daripada sisa ini. Agropreneur perlu berupaya mengoptimumkan penggunaan SMS agar sumber bernilai ini tidak dibaziri, selain menguruskan proses lepas tuai tanaman secara mesra alam.

\section{Metod dan kawasan kajian}

Reka bentuk kajian kuantitatif (survei) dan kualitatif (temu bual) digunakan bagi kajian pengetahuan potensi SMS dan pengurusan lepas tuai tanaman cendawan dalam kalangan agropreneur tanaman cendawan di Kedah dan Johor. Analisis deskriptif iaitu peratusan dilakukan bagi meneliti tahap pengetahuan terhadap potensi penggunaan SMS. Kajian turut memperlihatkan kaedah pengurusan SMS dan sisa beg cendawan yang diamalkan oleh agropreneur. Hal ini dapat memperlihatkan keupayaan agropreneur dalam pengurusan tanaman cendawan secara mesra alam. Metod triangulasi data dengan menggabungkan kaedah soal selidik, temu bual dan pemerhatian dilaksanakan. Temu bual bersama agropreneur dan kaedah pemerhatian dijalankan di lokasi perusahaan cendawan bagi meneliti secara mendalam kaedah pengurusan sisa substrat cendawan yang dilaksanakan oleh agropreneur. Kaedah pemerhatian ini memberi gambaran jelas kesan pengurusan SMS secara tidak mesra alam terhadap persekitaran tani dan penduduk setempat.

Rasional pemilihan Johor sebagai kawasan kajian kerana kadar penglibatan agropreneur dalam tanaman cendawan adalah tertinggi di Malaysia. Kedah pula berada dalam kedudukan kedua tertinggi dari aspek pengeluaran cendawan. Maklumat agropreneur berdaftar diperolehi melalui Jabatan Pertanian, namun terdapat juga agropreneur yang tidak berdaftar dengan Jabatan Pertanian. Justeru itu, kaedah persampelan bola salji (snowball sampling) digunakan dengan meminta responden mencadangkan subjek lain yang mempunyai ciri-ciri yang sama iaitu menjalankan perusahaan tanaman cendawan secara komersil. Jumlah populasi agropreneur tanaman cendawan yang diperolehi di Kedah ialah seramai 44 orang, manakala di Johor seramai 47 orang. Berdasarkan jadual penentuan saiz sampel Krejcie dan Morgan (1970), jumlah sampel yang ditentukan ialah di Kedah adalah 36 orang responden dan Johor pula seramai 42 orang responden.

\section{Hasil kajian dan perbincangan}

\section{Profil agropreneur}

Majoriti agropreneur terdiri daripada lelaki iaitu 61.1\% di Kedah dan di Johor seramai 85.7\%. Data menunjukkan jantina lelaki mendominasi perusahaan tanaman cendawan yang dijadikan sebagai satu pekerjaan tetap ketua isi rumah. Hasil kajian menunjukkan $77.8 \%$ di Kedah dan 90.5\% di Johor menjadikan perusahaan tanaman cendawan sebagai pekerjaan tetap (Jadual 1). Berdasarkan temu bual, hanya sebilangan kecil golongan perempuan mengusahakan tanaman cendawan untuk membantu meningkatkan pendapatan isi rumah.

Kategori umur agropreneur paling ramai yang terlibat dalam perusahaan tanaman cendawan di Kedah terdiri daripada golongan belia yang berumur antara 31 hingga 40 tahun $(52.8 \%)$. Di Johor, turut diusahakan oleh golongan belia berumur dalam lingkungan 31 hingga 
40 tahun (23.8\%), namun majoriti usahawan berumur antara 51 hingga 60 tahun dengan peratusan adalah 31.0\%. Majoriti agropreneur adalah berbangsa Melayu iaitu $91.7 \%$ di Kedah dan $71.4 \%$ di Johor, manakala selebihnya adalah berbangsa Cina (Jadual 1).

Jadual 1. Profil agropreneur

\begin{tabular}{|c|c|c|c|c|}
\hline \multirow[t]{2}{*}{ Profil } & \multicolumn{2}{|c|}{ Kedah } & \multicolumn{2}{|c|}{ Johor } \\
\hline & Bilangan $(n=36)$ & Peratus (\%) & Bilangan $(n=42)$ & Peratus (\%) \\
\hline \multicolumn{5}{|l|}{ Jantina } \\
\hline Lelaki & 22 & 61.1 & 36 & 85.7 \\
\hline Perempuan & 14 & 38.9 & 6 & 14.3 \\
\hline \multicolumn{5}{|l|}{ Umur } \\
\hline 30 tahun ke bawah & 5 & 13.9 & 4 & 9.5 \\
\hline $31-40$ tahun & 19 & 52.8 & 10 & 23.8 \\
\hline $41-50$ tahun & 6 & 16.7 & 11 & 26.2 \\
\hline 51-60 tahun & 4 & 11.1 & 13 & 31.0 \\
\hline 61 tahun ke atas & 2 & 5.6 & 4 & 9.5 \\
\hline \multicolumn{5}{|l|}{ Bangsa } \\
\hline Melayu & 33 & 91.7 & 30 & 71.4 \\
\hline Cina & 3 & 8.3 & 12 & 28.6 \\
\hline \multicolumn{5}{|l|}{ Status pekerjaan } \\
\hline Pekerjaan tetap & 28 & 77.8 & 38 & 90.5 \\
\hline Pekerjaan sampingan & 8 & 22.2 & 4 & 9.5 \\
\hline
\end{tabular}

\section{Profil perusahaan tanaman cendawan}

Terdapat lima jenis cendawan yang diusahakan secara komersil di Kedah dan Johor iaitu Tiram kelabu, Tiram putih, Kukur, Abalon dan Ling zhi. Kebanyakan cendawan yang dijual di pasaran berbentuk segar, kecuali Ling zhi yang dipasarkan dalam bentuk kering.

Majoriti agropreneur di Kedah memfokus kepada perusahaan tanaman cendawan Tiram kelabu sahaja iaitu seramai 34 orang (94.4\%) dan 39 orang (92.9\%) di Johor. Fokus agropreneur kepada tanaman cendawan Tiram kelabu adalah kerana permintaan yang tinggi dalam kalangan masyarakat berbilang kaum di Malaysia iaitu Melayu, Cina dan India terhadap jenis cendawan ini. Segelintir agropreneur di Kedah pula mengusahakan dua atau tiga jenis cendawan pada satusatu masa. Seramai lapan orang responden (22.3\%) mengusahakan gabungan cendawan Tiram kelabu dan Tiram putih serta Kukur dan Abalon. Manakala di Johor, hanya tiga orang (7.1\%) dengan tumpuan kepada cendawan Tiram kelabu dan Kukur sahaja. Hal ini kerana terdapat juga permintaan terhadap pelbagai jenis cendawan daripada penduduk sekitar. Tanaman cendawan Ling zhi (5.6\%) di Kedah dikomersilkan di peringkat tempatan dan antarabangsa sebagai produk makanan kesihatan dan kecantikan (Jadual 2).

Jadual 2. Jenis cendawan yang diusahakan oleh agropreneur

\begin{tabular}{lcccc}
\hline Jenis Cendawan & \multicolumn{2}{c}{ Kedah } & \multicolumn{2}{c}{ Johor } \\
\cline { 2 - 5 } & Bilangan $(\mathbf{n}=\mathbf{3 6})$ & Peratus & Bilangan $(\mathbf{n = 4 2})$ & Peratus \\
\hline Tiram kelabu & 34 & 94.4 & 39 & 92.9 \\
Tiram kelabu + Tiram putih & 6 & 16.7 & - & - \\
Tiram kelabu + Kukur & 1 & 2.8 & 3 & 7.1 \\
Tiram kelabu + Tiram putih + Abalon & 1 & 2.8 & - & - \\
Ling zhi & 2 & 5.6 & - & - \\
\hline
\end{tabular}




\section{Tahap pengetahuan agropreneur terhadap potensi sisa substrat cendawan}

Umumnya, SMS berpotensi digunakan semula sebagai substrat untuk tanaman cendawan atau dijadikan baja kompos untuk tanaman hortikultur. Kebanyakan agropreneur mempunyai pengetahuan yang tinggi bahawa SMS berpotensi digunakan semula sebagai baja kompos dan substrat untuk semaian tanaman. Hasil kajian mendapati 94.4\% agropreneur di Kedah dan 97.6\% agropreneur di Johor mengetahui bahawa SMS boleh digunakan semula sebagai baja kompos (Jadual 3). Temu bual mendapati majoriti agropreneur mengetahui bahawa SMS mengandungi nutrien yang tinggi kerana substrat ini juga merupakan sisa tanaman lain. Hal ini disokong oleh Ahlawat \& Sagar (2007), Ahlawat dan Tewari (2007), Marshall dan Nair (2009), Marques et al. (2014) dan Zhang et al. (2014) yang mendapati SMS sangat sesuai dijadikan baja kompos untuk tanaman hortikultur. Hal ini kerana SMS mengandungi NPK dan nutrien lain yang tinggi sesuai untuk meningkatkan kesuburan tanih dan pertumbuhan tanaman (Ahlawat \& Sagar, 2007; Grimm \& Wösten, 2018; Nik Nor Izyan et al., 2009; Ma et al., 2014).

Begitu juga penggunaan SMS sebagai vermikompos yang hanya diketahui penggunaannya oleh tujuh orang agropreneur $(19.4 \%)$ di Kedah dan lima orang agropreneur (26.2\%) di Johor (Jadual 3). Kajian Ahlawat dan Sagar (2007) dan Nik Nor Izyan et al. (2009) menyokong bahawa SMS sangat berpotensi digunakan semula sebagai vermikompos yang diproses melalui medium pembiakan cacing.

Jadual 3. Tahap pengetahuan agropreneur terhadap potensi sisa substrat cendawan

\begin{tabular}{lcccc}
\hline $\begin{array}{l}\text { Tahap pengetahuan terhadap potensi } \\
\text { sisa substrat cendawan }\end{array}$ & \multicolumn{2}{c}{ Kedah } & \multicolumn{2}{c}{ Johor } \\
\cline { 2 - 5 } & Bilangan (n=36) & Peratus & Bilangan (n=42) & Peratus \\
\hline Baja kompos & 34 & 94.4 & 41 & 97.6 \\
Substrat semaian tanaman & 14 & 38.9 & 11 & 11.9 \\
Vermikompos & 7 & 19.4 & 5 & 26.2 \\
Substrat tanaman cendawan & 3 & 8.3 & 2 & 4.8 \\
Meningkatkan kandungan nutrien dan agen & 2 & 5.6 & 2 & 4.8 \\
baik pulih struktur tanih & & & & - \\
Sumber alternatif bahan api fosil & - & - & - & - \\
\hline
\end{tabular}

Sisa substrat cendawan juga boleh digunakan semula untuk dijadikan substrat semaian tanaman. Seramai 25 orang agropreneur mengetahui potensi SMS sebagai kegunaan substrat semaian tanaman iaitu 14 orang (38.9\%) di Kedah dan 11 orang (26.2\%) di Johor (Jadual 3). Ini bertepatan dengan kajian Marques et al. (2014) yang melihat keupayaan SMS sebagai semaian tanaman hortikultur.

Penggunaan semula SMS untuk tanaman cendawan berikutnya atau tanaman cendawan lain hanya diketahui oleh tiga orang agropreneur (8.3\%) di Kedah dan dua orang (4.8\%) di Johor (Jadual 3). Temu bual mendapati agropreneur yang mengetahui tentang potensi tersebut turut membuat kajian berkaitan kelebihan penggunaan SMS sebagai substrat untuk tanaman cendawan. Hasilnya, ada dalam kalangan mereka yang menggunakan semula SMS untuk tanaman cendawan berikutnya. Hanya empat orang agropreneur mengetahui potensi SMS sebagai agen meningkatkan kandungan nutrien dan penambahbaikan struktur tanih iaitu seramai dua orang di Kedah (5.6\%) dan dua orang di Johor (4.8\%) (Jadual 3). Hal ini dibuktikan oleh kajian Landschoot dan McNill, (2019), Ehtesham dan Vakili (2015) serta Naresh (2013) yang mendapati penggunaan SMS mampu menjadikan struktur lapisan atas tanih (topsoil) menjadi 
lebih baik, selain menyeimbangkan permintaan ekologi terhadap sistem pengeluaran tanaman (Naresh, 2013).

Kajian membuktikan bahawa SMS telah berjaya dibangunkan sebagai sumber bahan api (Finney et al., 2009; Ma et al., 2014; Meera et al., 2014; Pérez-Chávez et al., 2019; Oei et al. 2007). Namun begitu, tiada agropreneur di kedua-dua kawasan kajian mengetahui bahawa SMS berpotensi dijadikan sebagai sumber alternatif bagi menggantikan penggunaan bahan api fosil antaranya gas metana dan biogas untuk tujuan pemanasan serta memasak. Oleh itu, sumber SMS ini tidak dieksploitasi sebagai sumber bahan api alternatif oleh agropreneur di kedua-dua kawasan kajian ini.

\section{Kaedah pengurusan lepas tuai tanaman cendawan}

a. Kaedah pengurusan sisa substrat cendawan

Berdasarkan temu bual, kesediaan agropreneur untuk menguruskan SMS secara mesra alam sangat bergantung kepada keadaan sisa substrat, cuaca dan sikap agropreneur. Kekangan utama dalam pengurusan SMS secara mesra alam adalah bergantung kepada keadaan sisa substrat iaitu diserang penyakit dan serangga perosak. Sekiranya bongkah cendawan diserang penyakit dan serangga perosak, bongkah cendawan perlu dihapuskan dengan kadar segera. Kaedah sebaiknya dilakukan melalui pembakaran bagi mengelakkan serangan merebak kepada tanaman lain ataupun tanaman berikutnya. Ini bertepatan dengan kajian oleh Rosmiza dan Juliana (2017) yang mendapati pengurusan lepas tuai secara mesra alam bergantung kepada keadaan bongkah cendawan, cuaca serta sikap agropreneur itu sendiri.

Majoriti agropreneur memilih kaedah yang tidak mesra alam dengan melonggokkan SMS di tempat pembuangan lain yang tidak teratur iaitu 72.2\% di Kedah dan 85.7\% di Johor (Jadual 4). Hasil pemerhatian mendapati agropreneur membuang SMS ke tempat pembuangan yang agak jauh daripada rumah cendawan bagi mengelakkan bau busuk. Dapatan ini adalah selari dengan kajian oleh Ahlawat dan Sagar (2007), Ehtesham dan Vakili (2015), Grimm dan Wösten (2018), Philipousis (2009) dan Rosmiza et al. (2016) yang menyatakan pengurusan SMS yang tidak sempurna akan menyebabkan pencemaran bau ke atas kawasan persekitaran tani.

Kaedah lain yang sering diamalkan oleh agropreneur adalah membakar SMS secara terbuka iaitu 11 orang agropreneur (30.6\%) di Kedah dan 11 orang (26.2\%) di Johor (Jadual 4). Kaedah ini juga merupakan kaedah yang sering dipraktikkan oleh usahawan di peringkat tempatan dan luar negara yang mendatangkan kesan ke atas alam sekitar (Finney et al., 2009; Rosmiza dan Juliana (2017). Temu bual mendapati kaedah tersebut dipilih kerana mudah dan murah untuk menguruskan sisa bongkah cendawan. Hasil kajian ini bertepatan dengan kajian Chang \& Wasser (2017), Naresh (2013), Phan dan Sabaratnam (2012) serta Rosmiza et al. (2018) yang menyatakan bahawa kaedah pengurusan lepas tuai yang sering dipraktikkan oleh agropreneur adalah yang mudah dan murah untuk pembersihan ladang. Kaedah pembuangan SMS di tempat lain dan pembakaran turut dilakukan bertujuan mengelak penularan penyakit tanaman dan serangan perosak kepada tanaman cendawan sedia ada dan tanaman berikutnya.

Pemerhatian turut mendapati terdapat dua orang agropreneur di kedua-dua kawasan kajian melonggokkan sisa bongkah cendawan di dalam saliran air berdekatan kawasan ladang (Jadual 4). Hal ini menyebabkan saliran air agak tersekat dan berbau.

Hasil kajian mendapati terdapat tiga kaedah mesra alam yang dipraktikkan oleh agropreneur di kawasan kajian iaitu SMS dikomposkan, dijual kepada pihak tertentu dan 
penggunaan semula sebagai substrat tanaman cendawan. Seramai 10 orang (27.8\%) agropreneur di Kedah dan 15 orang (35.7\%) di Johor menggunakan semula SMS sebagai kompos (Jadual 4). Namun begitu, mereka hanya menggunakannya untuk tanaman hiasan di halaman rumah sahaja.

Kelebihan nutrien yang terdapat dalam SMS menyebabkan penggunaannya sebagai substrat bagi tanaman cendawan lain adalah sangat baik. Namun begitu, hanya seorang sahaja agropreneur di Johor yang menggunakan semula SMS untuk tanaman cendawan berikutnya Tanamannya didapati lebih subur dan hasil pengeluaran lebih baik berbanding sebelumnya. Hal ini disokong oleh kajian Ashrafi et al. (2014), Josephine (2014), Oei et al. (2007), Siddhant dan Singh (2009), Royse (1992), Taiwan Agricultural Research Institute (2012) dan Yoshida et al. (1993) yang menjelaskan SMS sangat sesuai digunakan sebagai substrat bagi tanaman cendawan lain, malahan menjadikan tanaman lebih subur dan hasil pengeluaran lebih tinggi.

Hanya seorang sahaja agropreneur di Kedah yang menjual SMS kepada pengusaha nurseri pokok bunga (Jadual 4). Temu bual mendapati hasil jualan SMS dapat menjana pendapatan sampingan kepada usahawan yang selari dengan pandangan Josephine (2014), Peng (2010) dan Tuhy et al. (2015).

Jadual 4. Kaedah pengurusan sisa substrat cendawan

\begin{tabular}{lcccc}
\hline Kaedah pengurusan & $\begin{array}{c}\text { Kedah } \\
\text { Bilangan }(\mathbf{n = 3 6})\end{array}$ & Peratus & Bilangan $(\mathbf{n = 4 2})$ & Peratus \\
\hline $\begin{array}{l}\text { Kaedah tidak mesra alam } \\
\text { Dilonggokkan di tempat pembuangan }\end{array}$ & 26 & 72.2 & 36 & 85.7 \\
tidak teratur & & & & 26.2 \\
$\quad \begin{array}{l}\text { Dibakar secara terbuka } \\
\text { Dibuang ke dalam longkang/ parit }\end{array}$ & 11 & 30.6 & 11 & 4.8 \\
Kaedah mesra alam & 2 & 5.6 & 2 & 35.7 \\
$\quad$ Dikomposkan & 10 & 27.8 & 15 & - \\
$\quad \begin{array}{l}\text { Dijual kepada pihak tertentu } \\
\text { Substrat tanaman cendawan lain }\end{array}$ & 1 & 2.8 & - & 2.4 \\
\hline
\end{tabular}

Berdasarkan temu bual, keseluruhan agropreneur amat mementingkan kebersihan kawasan dalaman rumah cendawan agar hasil yang diperolehi adalah tinggi. Hal ini kerana tanaman cendawan amat sensitif kepada persekitaran yang kurang bersih dan tercemar. Namun begitu, hasil pemerhatian mendapati agropreneur kurang memberi penekanan terhadap aspek kebersihan persekitaran luar ladang. Hal ini menyebabkan agropreneur melonggokkan, membakar dan membuang SMS di tempat yang tidak teratur dan sempurna.

\section{b. Kaedah pengurusan sisa beg cendawan}

Sisa substrat cendawan yang dikomposkan atau digunakan semula akan meninggalkan sisa beg cendawan (plastik bongkah cendawan). Hasil kajian mendapati terdapat tiga kaedah yang dipraktikkan oleh agropreneur dalam pengurusan sisa beg cendawan. Majoriti agropreneur memilih untuk melonggokkan sisa beg cendawan di tempat pembuangan iaitu di Kedah (75.0\%) dan di Johor (95.2\%). Seramai 14 orang agropreneur (38.9\%) di Kedah dan 15 orang agropreneur (35.7\%) di Johor, lazimnya membakar sisa beg cendawan (Jadual 5). Terdapat dua orang agropreneur sering memilih kaedah pembuangan ke dalam longkang atau parit yang berdekatan dengan persekitaran ladang. 
Jadual 5. Kaedah pengurusan sisa beg cendawan

\begin{tabular}{lcccc}
\hline Kaedah pengurusan & \multicolumn{2}{c}{ Kedah } & \multicolumn{2}{c}{ Johor } \\
\cline { 2 - 5 } & Bilangan $(\mathbf{n = 3 6})$ & Peratus & Bilangan $(\mathbf{n = 4 2})$ & Peratus \\
\hline Dilonggokkan di tempat pembuangan & 27 & 75.0 & 40 & 95.2 \\
Dibakar secara terbuka & 14 & 38.9 & 15 & 35.7 \\
Dibuang ke dalam longkang/ parit & 2 & 5.6 & 2 & 4.8 \\
\hline
\end{tabular}

Kesemua kaedah yang dipraktikkan oleh agropreneur dalam pelupusan sisa beg cendawan adalah bersifat tidak mesra alam. Temu bual mendapati agropreneur mengetahui bahawa kaedah yang dipraktikkan menyebabkan pencemaran ke atas persekitaran tani seperti pencemaran udara dan air, namun kaedah inilah yang paling murah dan mudah untuk pengurusan sisa beg cendawan selari dengan dapatan kajian oleh Rosmiza et al. (2018).

\section{Kesimpulan}

Tanaman cendawan merupakan sejenis tanaman yang boleh mempraktikkan amalan mesra alam bermula peringkat proses penanaman iaitu menggunakan sisa tanaman sebagai substrat tanaman sehinggalah lepas tuai dengan menggunakan semula SMS tersebut. Namun begitu, agropreneur kurang mempraktikkan amalan mesra alam pada peringkat lepas tuai dengan lebih memilih kepada kaedah yang mudah dan murah dalam pengurusan ladang iaitu melonggokkan di tempat pembuangan dan membakarnya secara terbuka. Kaedah ini menyebabkan berlakunya kemerosotan ke atas alam sekitar seperti pencemaran udara dan air, menjejaskan pandangan persekitaran serta menimbulkan ketidakselesaan kepada penduduk sekitar. Hal ini disebabkan agropreneur kurang mengetahui potensi yang boleh dibangunkan daripada SMS. Justeru itu, mereka perlu ditingkatkan pemahaman tentang penjagaan alam sekitar dalam pengurusan lepas tuai, selain diberi latihan serta kemahiran untuk mengoptimumkan potensi SMS dalam aktiviti huluan dan hiliran. Pembangunan sumber sedia ada ini bakal membuka peluang penjanaan pendapatan sampingan kepada agropreneur berteraskan konsep penjanaan kekayaan daripada sisa buangan melalui perniagaan tani secara hijau. Oleh itu, peranan agensi pertanian dan pihak berkepentingan lain adalah penting dalam membangunkan serta menyebarkan potensi dan kepentingan penjagaan alam sekitar dalam pengurusan lepas tuai tanaman. Lantaran itu, agropreneur berupaya menjana pendapatan sampingan melalui aktiviti hiliran, selain dapat mengurangkan kos pengurusan ladang melalui penggunaan semula SMS sebagai substrat tanaman cendawan berikutnya. Pengurusan sisa tanaman mesra alam ini akan membawa kepada perluasan ekonomi setempat dan persekitaran tani yang sihat.

\section{Penghargaan}

Setulus penghargaan kepada Universiti Kebangsaaan Malaysia atas pemberian dana Geran Universiti Penyelidikan (GUP 2016-023). 


\section{Rujukan}

Ahlawat, O.P., \& Sagar, M.P. (2007). Management of spent mushroom substrate. National Research Centre for Mushroom, Indian Council of Agricultural Research.

Ahlawat, O.P., \& Sagar, M.P. (2011). Recycling of spent mushroom substrate to use as organic manure. National Research Centre for Mushroom, Indian Council of Agricultural Research.

Ahlawat, O.P., \& Tewari, R.P. (2007). Cultivation technology of paddy straw mushroom (Volvariella volvacea). National Research Centre for Mushroom, Indian Council of Agricultural Research.

Ashrafi, R., Mianm, M.H., Rahman, M.M., \& Jahiruddin. (2014). Recycling of spent mushroom substrate for the production of oyster mushroom. Research in Biotechnology, 5(2), 13-21.

Beetz, A., \& Kustudia, M. (2004). Mushroom cultivation and marketing. National Sustainable Agriculture Information Service. Retrieved from www.attra.ncat.org

Bharani, A., Somasundaram, E., \& Nandhini, D.U. (2019). Organic farming: A way forward for sustainable agriculture. In Karthikeyan, C., \& Sendilkumar, R. (Eds.). Sustainable development through innovative agriculture. (pp.137-146). New Delhi, Daya Publishing House.

Chang, S.T., \& Wasser, S.P. (2017). The cultivation and environmental impact of mushrooms. In Agriculture and the environment. 25-39. DOI:10.1093/acrefore/9780199389414.013.231.

Dang Lelamurni Abd. Razak. (2013). Cultivation of auricularia polytricha mont. sacc (Black jelly mushroom) using oil palm wastes. (Masters dissertation). Retrieved from Jabatan Sains, Universiti Malaysa.

Ehtesham, S., \& Vakili, A.R. (2015). The effect of spent mushroom substrate on blood metabolites and weight gain in Kurdish male lambs. Entomology and Applied Science, 2(1), 29-33.

Elenwo, E.N., \& Okere, S.E. (2007). Waste re-cycling using edible mushroom cultivation. Journal Applied Sciences and Environment Management, 11(3), 153-156.

Finney, K.N., Ryu, C., Sharifi, V.N., Swithenbank, J. (2009). The reuse of spent mushroom compost and coal tailings for energy recovery: Comparison of thermal treatment technologies. Bioresour Technol, 100, 310-315.

Food and Fertilizer Technology Center. (2002). Mushroom cultivation using rice straw as a culture media. Retrieved from http://www.fftc.agnet.org/library

Grimm, D., \& Wösten, H.A.B. (2018). Mushroom cultivation in the circular economy. Applied Microbiology and Biotechnology, 102, 7795-7803. https://doi.org/10.1007/s00253-0189226-8.

Hoa, H.T., Wang, C.L., \& Wang, C.H. 2015. The effects of different substrates on the growth, yield and nutritional composition of two oyster mushrooms (Pleurotus ostreatus and Pleurotus cystidiosus). Mycobiology, 43(4). 423-434.

Josephine, M. 2014. Solid waste management through mushroom cultivation - An eco friendly approach. International Journal of Environmental and Ecological Engineering, 8(2), 115117.

Josephine, R.M., \& Sahana, B. (2014). Cultivation of milky mushroom using paddy straw waste. International Journal of Current Microbilogy and Applied Sciences, 3(12), 404-408.

Kementerian Pertanian dan Industri Asas Tani. (2011). Dasar Agromakanan Negara 2011-2010. Kuala Lumpur, Percetakan Watan. 
Krejcie, R.V., \& Morgan, D.W. (1970). Determining sample size for research activities. Educational and Psycological Measurement, 30, 608-610.

Kumar, P., Kumar, S., Lal, M., \& Mohd. Ali. (2013). Mushroom cultivation: An emerging agribusiness for self-employment and entrepreneur development. Agriways, 1(2), 147-154.

Landschoot, P., \& McNitt, A. (2019). Spent mushroom substrate as a soil amendment in turf. Retrieved from https:// extension.psu.edu.

Laufenberg, G., Kunz, B., Nystroem, M. (2003). Transformation of vegetable waste into value added products: (A) the upgrading concept; (B) practical implementations. Bioresources Technology, 87(2), 167-198.

Law, W.M., Lau, W.N., Lo, K.L., Wai, L.M., \& Chiu, S.W. (2003). Removal of biocide pentachlorophenol in water system by the spent mushroom compost of Pleurotus pulmonarius. Chemosphere, 52(9), 1531-1537.

Lou, Z., Sun, Y., Bian, S., Baig, S.A., Hu, B., \& Xu, X. 2017. Nutrient conservation during spent mushroom compost application using spent mushroom substrate derived biochar. Chemosphere, 169, 23-31.

Ma, Y., Wang, Q., Sun, X., Wang, X., Su, W., Song, N. (2014). A study on recycling of spent mushroom substrate to prepare chars and activated carbon. Bioresources, 9(3), 3939-3954.

Mamiro, D.P., \& Mamiro, P.S. (2011). Yield and mushroom size of Pleurotus ostreatus grown on rice straw basal substrate mixed and supplemented with various crop residues. Journal of Animal and Plant Sciences, 10, 1211-1218.

Marques, E.L.S., Martos, E.T., Souza, R.J., Silva, R., Zied, D.C., \& Dias, E.S. (2014). Spent mushroom compost as a substrate for the production of lettuce seedlings. Journal of Agricultural Sciences, 6(7), 138-143.

Marshall, E., \& Nair, N. G. (2009). Make money by growing mushrooms. Rome, Food and Agriculture Organization (FAO) of the United Nations.

Medina, E., Paredes, C., Bustamante, M.A., Moral, R., \& Moreno-Caselles, J. (2012). Relationships between soil physico-chemical, chemical and biological properties in a soil amended with spent mushroom substrate. Geoderma, 173(174), 152-161.

Meera, P., Senthil Kumaran, G., \& Vasudeo, G. (2014). Making mushroom production process a zeo waste enterprise. International Journal of Environmental Sciences, 5(2), 236-242.

Mohd Tarmizi, H., Hairazi, R., \& Rozhan, A.D. (2013). Understanding the mushroom industry and its marketing strategies for fresh produce in Malaysia. Economic and Technology Management Review, 8, 27-37.

Naresh, R.K. (2013). Rice residues: From waste to wealth through environment friendly and innovative management solutions, its effects on soil properties and crop productivity. International Journal of Life Sciences Biotechnology and Pharma Research, 2, 133-141.

Nik Nor Izyan, Adi Ainurzaman, \& Nor Zalina Mahmood. (2009). Potential of spent mushroom substrate in vermicomposting. Kuala Lumpur, University of Malaya.

Oei, P., Zeng, H. Liao, J., Dai, J., Chem, M., \& Yi, C. (2007). The alternative uses of spent mushroom compost. Innovatie Network Reports, April 2007.

Oluwalana, S.A., Adegbenjo, E.A., \& Oluwalana, E.O. (2016. Enhancing food security: Cultivation of oyster mushroom (Pleurotus sajor-caju) using agroforestry wastes. Advance in Forestry Science, 3(2), 25-28.

Pani, B., Panda, S., \& Das, S. (1997). Utilization of some by-products and other wastes for sporophore production of oyster mushroom. Orissa Journal Horticulture, 25, 36-39. 
Peng, J.T. (2010). Agro-waste for cultivation of edible mushrooms in Taiwan. Food and Fertilizer Technology Center. Retrieved from www.agnet.org.

Pérez-Chávez, A.M., Mayer, L., \& Alberto, E. (2019). Mushroom cultivation and biogas production: A sustainable reuse of organic resources. Energy for Sustainable Development, 50, 50-60.

Phan, C.W., \& Sabaratnam, V. (2012). Potential uses of spent mushroom substrate and its associated lignocellulosic enzymes. Applied Microbiology and Biotechnology, 96, 863-873.

Philippoussis, A.N. 2009. Production of mushrooms using agro-industrial residues as substrates. In Singh nee' Nigam, P., \& Pandey, A. (Eds.). Biotechnology for agro-industrial residues. Springer, Dordrecht. https://doi.org/10.1007/978-1-4020-9942-7_9

Rinker, D.L. (2002). Handling and using "spent" mushroom substrate around the world. Proceedings of the $4^{\text {th }}$ International Conference on Mushroom Biology and Mushroom Products. 43-60.

Rinker, D. L. (2005). Recycling spent Shiitake substrate. Mushroom Grower' Handbook 2. Retrieved from www. Alohamedicinals.com.

Rosmiza M.Z. \& Juliana Mah Hussin. (2017). Kecenderungan penglibatan agropreneur dalam industri tanaman cendawan di Selangor. Geografia-Malaysian Journal of Society and Space, 13(4), 37-46.

Rosmiza, M.Z., Davies, W.P., Rosniza Aznie, C.R., Jabil, M.J., \& Mazdi, M. (2016). Prospects for increasing commercial mushroom production in Malaysia: Challenges and opportunities. Mediterranean Journal of Social Sciences, 7(1), 406-415.

Rosmiza, M., Davies, W., Rosniza, C.R., Jabil, M., Mazdi, M., Toren, W.W., \& Rosmawati, C.C. (2015). Stagnation of rice straw agribusiness development in Malaysia: The entrepreneurs' perspectives. Mediterranean Journal of Social Sciences, 6(4), 523-530.

Rosmiza, Mohd Zainol, Mohd Nazri Mohd Tamami, Rosniza Aznie Che Rose, Jabil Mapjabil, \& Mazdi Marzuki. (2018). Kaedah Pengurusan Sisa substrat cendawan dalam kalangan agropreneur muda cendawan. Geografi, 6(3), 67-75.

Royse, D.J. (1992). Recycling of spent shiitake substrate for production of the oyster mushroom, Pleurotus sajor-caju. Appl Microbiol Biotechnol, 38, 179-182.

Royse, D.J., \& Baars, J.J.P. (2017). Current overview of mushroom production in the world: Technology and applications. In. Edible and Medicinal Mushrooms. (pp.5-13). DOI: $10.1002 / 9781119149446 . c h 2$.

Siddhant \& Singh, C.S. (2009). Recycling of spent oyster mushroom substrate to recover additional value. Kathmandu University Journal of Science, Engineering and Technology, 5(2), 66-71.

Taiwan Agricultural Research Institute. (2012). Alternatives substrates for growing mushrooms. Council of Agriculture. Retrieved from http://www.tari.gov.tw

Tesfaw, A., Tadesse, A., \& Kiros, G. (2015). Optimization of oyster (Pleurotus ostreatus) mushroom cultivation using locally available substrates and materials in Debre Berhan, Ethiopia. Journal of Applied Biology and Biotechnology, 3(1), 15-20.

Thongklang, N., \& Luangharn, T. (2016). Testing agricultural wastes for the production of Pleurotus ostreatus. Mycosphere, 7(6), 766-772.

Triyono, S., Haryanto, A., Telaumbanua, M., Dermiyati, Lumbanraja, J., \& Filip, T. (2019). International Journal of Recycling of Organic Waste in Agriculture. 1-12. https://doi.org/10.1007/s40093-019-0259-5 
Tuhy, L., Samoraj, M., Witkowska, Z., Wilk, R., \& Chojnacka, K. (2015). Using spent mushroom substrate as the base for organic-mineral micronutrient fertilizer-Field tests on maize. BioResources, 10(3), 5709-5719.

Uzun, I. (2004). Use of spent mushroom compost in sustainable fruit production. Journal of Fruit and Ornamental Plant Research, 12, 157-165.

$\mathrm{Xu}, \mathrm{C}$., Chunru, H., \& Tailor, D.C. (1992). Sustainable agricultural development in China. World Development, 20(8), 1127-1144.

Yildiz, S., Yildiz, U.C., Gezer, E.D., \& Temiz, A. (2002). Some lignocellulosic wastes used as raw material in cultivation of the Pleurotus ostreatus culture mushroom. Process Biochemistry, 38, 301-306.

Yoshida, N., Takahashi, T., Nagao, T., \& Chen, J. (1993) Effect of edible mushroom (pleurotus ostreatus) cultivation on in vitro digestibility of wheat straw and sawdust substrate. Journal of Japanese Society of Grassland Science, 39, 177-182.

Zhang, Y., Geng, W., Shen, Y., Wang, Y., \& Dai, Y. (2014). Edible mushroom cultivation for food security and rural development in China: Bio-innovation, technological dissemination and marketing. Sustainability, 6, 2961-2973.

Zheng, S., Liu, Q., Wang, H., \& Ng, T.B. (2002). Can edible mushrooms promote sustainability in Beijing. Mycological Research, 106, 754-756. 